\title{
ABORTO NA SUPREMA CORTE: O CASO DA ANENCEFALIA NO BRASIL
}

\author{
DEBORA DINIZ \\ Universidade de Brasília \\ ANA CRISTINA GONZALEZ VÉLEZ \\ OMS, Fundação Ford, UNFPA
}

\begin{abstract}
Resumo: Este artigo analisa o desafio jurídico e ético imposto pela anencefalia ao debate sobre direitos reprodutivos no Brasil. O fio condutor da análise é a ação de anencefalia apresentada ao Supremo Tribunal Federal em 2004. O artigo demonstra como o debate sobre o aborto provoca os fundamentos constitucionais da laicidade do Estado brasileiro e expõe a fragilidade da razão pública em temas de direitos reprodutivos, em especial sobre o aborto. Palavras-chave: aborto; interrupção da gestação; anencefalia; razão pública; Estado laico; Suprema Corte.
\end{abstract}

\section{Introdução}

[...] A integridade física e biológica da vida intra-uterina também está em jogo. Depois, o sofrimento em si não é alguma coisa que degrade a dignidade humana; é elemento inerente à vida humana. O remorso também é forma de sofrimento [...] Nem quero discorrer sobre o aspecto moral e ético - não me interessa - de como o sofrimento pode, em certas circunstâncias, até engrandecer pessoas [...].'

Essas foram algumas das palavras do juiz da Suprema Corte brasileira, Cezar Peluso, para justificar seu voto favorável à cassação da liminar que, durante quatro meses, autorizou mulheres a interromper a gestação em caso de anencefalia no feto. Uma liminar foi concedida pelo ministro Marco Aurélio de Mello à Argüição de Descumprimento de Preceito Fundamental (ADPF) proposta pela Confederação Nacional dos Trabalhadores na Saúde com assessoria da Anis: Instituto de Bioética, Direitos Humanos e Gênero, em abril de $2004 .^{2}$ A ADPF é um instrumento jurídico ainda pouco utilizado na jurisprudência brasileira, pois permite que a sociedade civil interpele diretamente a Suprema Corte.

${ }^{2}$ Luis Roberto BARROSO, 2005. 
A liminar que autorizava a interrupção da gestação em caso de anencefalia no feto foi cassada na sessão plenária da Suprema Corte, em 20 de outubro de 2004. Após quatro meses em vigência, a liminar foi derrubada por ter sido considerado necessário o julgamento prévio do instrumento jurídico utilizado para a apresentação da ação. A ADPF é um instrumento jurídico novo e pouco utilizado no País, e, segundo alguns dos juízes, era preciso primeiro um julgamento sobre o seu cabimento antes da concessão da liminar. Em 28 de abril de 2005, os juízes deliberaram pelo cabimento do instrumento, e o mérito da ação ainda está por ser julgado. Indiferente aos argumentos processuais que justificariam ou não a cassação da liminar, o cerne da sessão plenária foi uma extensa discussão metafísica sobre o início e o sentido da vida humana, um tema provocativo e ameaçador para as fronteiras da razão pública em um Estado laico. A expectativa é de que a audiência pública de instrução do processo ocorra no segundo semestre de 2008, sendo a segunda audiência pública da história do STF.

O argumento jurídico e ético proposto na ação era de que, por ser a anencefalia uma má-formação incompatível com a sobrevida do feto fora do útero, a interrupção da gestação neste caso não deveria ser tipificada como crime, mas como um procedimento médico amparado em princípios constitucionais como o direito à saúde, à dignidade, à liberdade e a estar livre de tortura. ${ }^{3} \mathrm{~A}$ estratégia argumentativa da ação foi a de demonstrar que outros princípios constitucionais devem fazer parte do debate público e político sobre - aborto. A anencefalia foi um recurso metodológico para a imposição de uma nova argumentação, ao permitir suplantar a retórica cristã tradicional do aborto como um atentado a uma vida humana em potencial. ${ }^{4}$

A anencefalia é um distúrbio de fechamento do tubo neural diagnosticável nas primeiras semanas de gestação. Por diversas razões, o tubo neural do feto não se fecha, deixando o cérebro exposto. ${ }^{5} \mathrm{O}$ líquido amniótico gradativamente dissolve a massa encefálica, impedindo o desenvolvimento dos hemisférios cerebrais. Não há tratamento, cura ou qualquer possibilidade de sobrevida de um feto com anencefalia. Em mais da metade dos casos, os fetos não resistem à gestação, e os poucos que alcançam o momento do parto sobrevivem minutos ou horas fora do útero. O Brasil é o quarto país do mundo em número de partos de fetos com anencefalia. ${ }^{6}$ Isso não significa que as mulheres brasileiras tenham uma maior propensão à gestação de fetos anencefálicos, mas sim que o Brasil possui uma das legislações mais restritivas, obrigando as mulheres a se manterem grávidas a despeito do diagnóstico da inviabilidade fetal.

O argumento jurídico e ético da ação apresentada à Suprema Corte baseou-se na certeza científica da impossibilidade da vida extra-uterina do feto. A anencefalia exige uma reconfiguração dos termos descritivos tradicionalmente utilizados no debate sobre 0 aborto em países com forte tradição moral cristã. Os principais argumentos morais contrários à legalização do aborto no Brasil amparam-se em valores cristãos sobre o sentido da existência ou do início da vida. Muito embora uma democracia laica não necessite de consenso religioso sobre essa matéria para legalizar o aborto, o debate sobre a anencefalia foi capaz de suplantar o dilema moral paralisante sobre a moralidade do aborto ao atestar a inviabilidade fetal. ${ }^{7}$ A superação da retórica tradicional que sustenta a imoralidade do aborto no pressuposto de que seria um ato contra uma vida em potencial permitiu que

\footnotetext{
${ }^{3}$ BARROSO, 2004.

${ }^{4}$ Debora DINIZ, 2007a.

${ }^{5}$ NATIONAL INSTITUTE OF NEUROLOGICAL DISORDERS AND STROKE, 2007.

${ }^{6}$ ANIS, 2004.

7 DINIZ, 2007b.
} 
novos argumentos éticos fossem colocados na mesa de discussões políticas.

Não havendo expectativa ou potencialidade de vida extra-uterina, qual bem jurídico ou social se protegeria ao proibir uma mulher de interromper a gestação? O que significa "integridade física e biológica da vida extra-uterina" no caso de anencefalia no feto? Como o sofrimento involuntário provocado pelo dever de se manter grávida pode dignificar ou engrandecer as mulheres? Como estender princípios éticos como a dignidade da pessoa humana a um feto senão por valores metafísicos? Não há respostas razoáveis para essas perguntas, exceto se deslocarmos o debate do campo da razão pública para o dos argumentos religiosos, um deslocamento que, inesperadamente, a Suprema Corte brasileira realizou ao cancelar a liminar de anencefalia.

Em matéria de aborto, a tendência legislativa brasileira é conservadora, o que pode vir a representar uma revisão dos dois permissivos legais do Código Penal, inclusive de forma a revogá-los ou torná-los ainda mais restritivos. Na última década, houve tentativas frustradas de emendas constitucionais para revogar os excludentes de penalidade do aborto ao sustentar o pressuposto moral do direito à vida do feto desde a fecundação. ${ }^{8}$ Por tocar em questões constitucionais, a interpretação jurídica corrente no País é de que o aborto é matéria do Congresso Nacional ou da Suprema Corte de Justiça. Muito embora o Congresso Nacional e a Suprema Corte sejam diferentes instâncias da razão pública, a compreensão corrente de democracia representativa no Brasil é a da legitimidade de um parlamentar em representar os interesses específicos de uma determinada comunidade moral. Causa pouca controvérsia política a existência de congressistas religiosos ou com base política confessional, cuja pauta legislativa é promover e defender os interesses específicos de suas comunidades morais de origem e não uma idéia de pluralismo moral razoável.

Essa compreensão equivocada da democracia representativa associada à forte influência da moral cristã na história política e social do Brasil abre espaço para diferentes compromissos com a razão pública laica entre diferentes representantes da estrutura básica da sociedade. No Brasil, o Congresso Nacional é considerado a expressão da democracia representativa, sendo a idéia de representação entendida no sentido estreito de cacofonia moral e não como a promoção de interesses defensáveis para a vida pública de um Estado laico a partir de uma pluralidade de argumentos. É nesse contexto de pouca cultura e tradição democrática que a Suprema Corte assume um papel ainda mais preponderante para garantir não apenas a secularização do Estado, mas principalmente que o confronto argumentativo dar-se-á em bases defensáveis e fundamentado na razão pública laica.

A compreensão de que um ministro da Suprema Corte e um parlamentar ocupam papéis políticos diferentes, mesmo que diante de casos idênticos, é uma peça-chave para analisar a cassação da liminar sobre anencefalia no Brasil. Os compromissos políticos e institucionais de um parlamentar ou de um juiz imprimem marcas em seus discursos jurídicos e éticos: é politicamente aceitável que um parlamentar represente uma determinada comunidade moral e, por isso, uma de suas missões possa ser garantir que os valores de sua comunidade estejam representados no debate legislativo. No cenário político brasileiro, é possível, por exemplo, imaginar um parlamentar cristão em defesa de um projeto de lei sobre o direito incondicional à vida do feto, ou seja, um árduo proponente do princípio moral da sacralidade da vida do feto. Não se considera ilegítimo que esse mesmo parlamentar fundamente um projeto de lei em termos religiosos, baseado em premissas e dogmas específicos à sua comunidade moral. A esfera legislativa brasileira é esse cenário

\footnotetext{
${ }^{8}$ Maria Isabel BALTAR, 1996.
} 
confuso de contraposição de diferentes comunidades morais e de construção do consenso sobreposto por parlamentares pouco dispostos ao diálogo democrático e muito comprometidos com suas comunidades morais de origem, e, por isso, a razão pública não é um compromisso argumentativo tão claro quanto para os juízes da Suprema Corte.

A razão pública é a forma legítima de expressão argumentativa daqueles que representam a estrutura básica de uma sociedade. No entanto, quanto menos secularizada for uma sociedade, como é o caso do Brasil em que símbolos religiosos estão presentes em quase todos os espaços oficiais do Estado, menor o grau de adesão à razão pública pelos estratos de menor poder político na estrutura básica. ${ }^{9}$ Um médico do sistema público de saúde, por exemplo, sente-se confortável para alegar "objeção de consciência" em uma situação de aborto em caso de estupro, mesmo que ocupe o cargo de responsável pelo serviço de saúde e não haja como substituí-lo de imediato. ${ }^{10}$

A objeção de consciência - um instrumento de garantia do poder médico e, em geral, somente acionado contra os interesses das mulheres em questões reprodutivas - é traduzida em termos do direito à diversidade moral de crenças ou da tolerância à diversidade moral. Assim como no caso dos parlamentares, há um equívoco nessa argumentação, pois - médico de um serviço público de saúde representa a moralidade laica da república e não sua moralidade privada. Nesse sentido, não há como se apelar para objeção de consciência diante da razão pública, o único fundamento possível dos direitos e deveres instituídos por um Estado democrático. É exatamente nesse contexto de pouca compreensão da laicidade do Estado como um bem comum, de intensa sacralização da ordem pública e de quase nenhuma adesão à razão pública em matéria de aborto, que os juízes da Suprema Corte representam o papel de principais guardiões da razão pública.

Vários são os fundamentos argumentativos da razão pública a serem seguidos por um juiz da Suprema Corte ao julgar um caso. A razoabilidade de seus argumentos e o compromisso com o consenso sobreposto são alguns deles. ${ }^{11}$ Um argumento é razoável quando pode ser expresso em termos públicos, o que na Suprema Corte pode ser medido pelo cumprimento dos princípios e das normas constitucionais. $O$ consenso sobreposto representa um conjunto de acordos firmados por diferentes comunidades morais de um Estado democrático e que, no caso específico do aborto em uma democracia laica, expressar-se-ia na garantia da neutralidade confessional dos argumentos. ${ }^{12}$ Isso significa que um juiz da Suprema Corte não pode ocupar o mesmo papel político que um parlamentar ao propor um projeto de lei sobre aborto no País: a razão pública e o compromisso com a laicidade são guias para o raciocínio moral e jurídico de um juiz, ao passo que muitas vezes não o é para um parlamentar.

A Suprema Corte é o ícone da razão pública em um Estado democrático. No caso brasileiro, os 11 ministros não apenas acreditam na centralidade da razão pública como pautam seus votos nesse raciocínio moral, pois são subordinados ao texto constitucional. 0 treino moral de um juiz da Suprema Corte parte do reconhecimento de que nem todas as crenças racionais são consideradas razoáveis para um Estado democrático de direito. No campo do aborto, isso pode significar que, muito embora uma determinada comunidade moral considere o aborto um atentado contra uma lei divina, esse não é um pressuposto moral defensável na esfera pública. O fato de uma crença moral ser racional, isto é, fundamentada, defendida e justificada por um grupo de pessoas e válida para uma

\footnotetext{
${ }^{9}$ Roberto LOREA, 2007.

${ }^{10}$ DINIZ, 2007a.

11 John RAWLS, 2000.

12 RAWLS, 2000.
} 
determinada comunidade moral, não significa que seja razoável para a esfera pública de um Estado plural e laico. Por diversas razões, nem toda crença racional é considerada razoável para a razão pública e, em matéria de aborto, grande parte dos valores que sustentam a imoralidade do aborto não respeita o princípio da laicidade do Estado ou do pluralismo moral razoável. O resultado desse acordo de argumentação moral é a segurança jurídica de que, apesar de um juiz participar de uma determinada comunidade moral em sua vida privada, como representante da razão pública seus julgamentos não se pautarão em suas crenças particulares.

Esse raciocínio moral e ordenamento institucional são satisfatoriamente cumpridos pelos juízes que alcançam a Suprema Corte. A razão pública deve ser não apenas um instrumento argumentativo para os juízes e os procuradores em sessões de julgamento, mas também uma garantia para a estabilidade democrática de um Estado constitucional. Nesse sentido, o compromisso com a razão pública - aqui representada pelo compromisso com a razoabilidade argumentativa e com a neutralidade confessional do Estado - permite uma análise dos posicionamentos dos juízes em seus próprios termos morais. A razão pública é a língua franca dos juízes da Suprema Corte, ao mesmo tempo que é um instrumento de controle democrático de seus posicionamentos. Poucos temas provocaram os juízes para além do caráter instrumental e de controle da razão pública, sendo o julgamento sobre a ação de anencefalia, e recentemente o da constitucionalidade da pesquisa com célulastronco embrionárias, raras exceções nesse cenário.

\section{Referências bibliográficas}

ANIS. Anencefalia: pensamento brasileiro em sua pluralidade. Brasília: LetrasLivres, 2004. BALTAR, Maria Isabel. "A questão do aborto no Brasil: o debate no Congresso". Revista Estudos Feministas, IFCS/UFRJ, n. 2, p. 381-398, 1996.

BARROSO, Luis Roberto. "Gestação de fetos anencefálicos e pesquisas com células-tronco: dois temas acerca da vida e da dignidade da pessoa humana". Revista de Direito Administrativo, Rio de Janeiro, v. 241, p. 93-120, 2005.

. "ADPF Anencefalia". In: CREMEB. Anencefalia e o Supremo Tribunal Federal, Brasília: LetrasLivres, p. 69-119, 2004.

DINIS, Debora. "Fórum Violência Sexual e Saúde". Cadernos de Saúde Pública, FIOCRUZ, v. 23, p. 477-478, 2007a. Posfácio.

. "Selective Abortion in Brazil: The Anencephaly Case". Developing World Bioethics, v. 7, n. 2, p. 21-28, 2007b.

LOREA, Roberto. Em defesa das liberdades laicas. Porto Alegre: Livraria do Advogado Editores, 2007.

NATIONAL INSTITUTE OF NEUROLOGICAL DISORDERS AND STROKE. NINDS Anencephaly Information Page. Bethesda, MD: NINDS, 2006. Disponível em: http://www.ninds.nih.gov/ disorders/anencephaly/anencephaly.htm. Acesso em: 25 maio 2007.

PELUSO, Cezar. Voto ADPF 54. Supremo Tribunal Federal Supremo, 20 out. 2004.

RAWLS, John. "Idéias fundamentais". In: . O liberalismo político. São Paulo: Ática, 2000. p. 46-91.

[Recebido em julho de 2008 e aceito para publicação em agosto de 2008] 


\section{Abortion at the Supreme Court: The Anencephaly Case in Brazil}

Abstract: This paper analyses the ethical and legal challenges of the anencephaly case in Brazil. The case study is the Supreme Court case on anencephaly proposed in 2004. This paper shows how the abortion debate forces the fundamentals of the Brazilian secular state and demonstrates the weakness of the public reason to mediate reproductive rights, mainly abortion, in Brazil.

Key Words: Abortion; Interruption of Pregnancy; Anencephaly; Public Reason; Secular State; Supreme Court. 